\title{
Making waves
}

\section{The voyage of HMS Challenger launched the science of oceanography.}

\author{
The Silent Landscape \\ by Richard Corfield \\ Joseph Henry/John Murray: 2003/2004. \\ 304 pp. $\$ 24.95 / £ 20$

\section{Charles Langmuir}

In 1874 the Challenger expedition left England on the maiden voyage of global ocean science. The results still reverberate within the community of sea-going scientists: all research vessels have some version of the Challenger results in their small libraries, and the phrase "as first discovered by the Challenger expedition" is often heard. The voyage discovered life in the deep sea and the complex thermohaline structure of the ocean. It provided the first samples of rocks from the ocean basins. It made possible a global map of ocean depths. And it initiated virtually every field of oceanography, from rocks to water to life. The Challenger results dealt with all these issues and more, in 50 volumes published over a period of 25 years after the ship returned to England in 1878.

Less well known are the rigours associated with this famous voyage. Today, oceangoing research is well established and an international fleet of oceanographic vessels continually traverses the oceans. Some 20 scientists and an equal number of crew experience a month at sea with the benefits of perfect navigation, the engine power to go anywhere at any time, and daily communications with land.

The Challenger expedition was heroic by comparison. Close to 300 people, including only six scientists, were crammed on to a ship half the size of modern research vessels. The expedition was largely under sail, and for four long years the scientists and crew endured ferocious storms, demoralizing calms, threatening icebergs, plagues in foreign ports, the tragic deaths of colleagues and friends, and had only infrequent communication with home.

As well as the scientific and human stories, the expedition has a rich historical context. The voyage emerged from a confluence of practical, political and scientific motivations. The communications revolution of the telegraph led to the need for better maps of the sea floor, and part of the expedition was devoted to planning routes for telegraph cables. England's sea power provided the expertise, resources and support in foreign ports to mount such a major research effort. The debates about evolution ignited by Darwin's theory of natural selection raised the question of the missing links between species that might be found in the sea, and there was a hot debate about whether life in

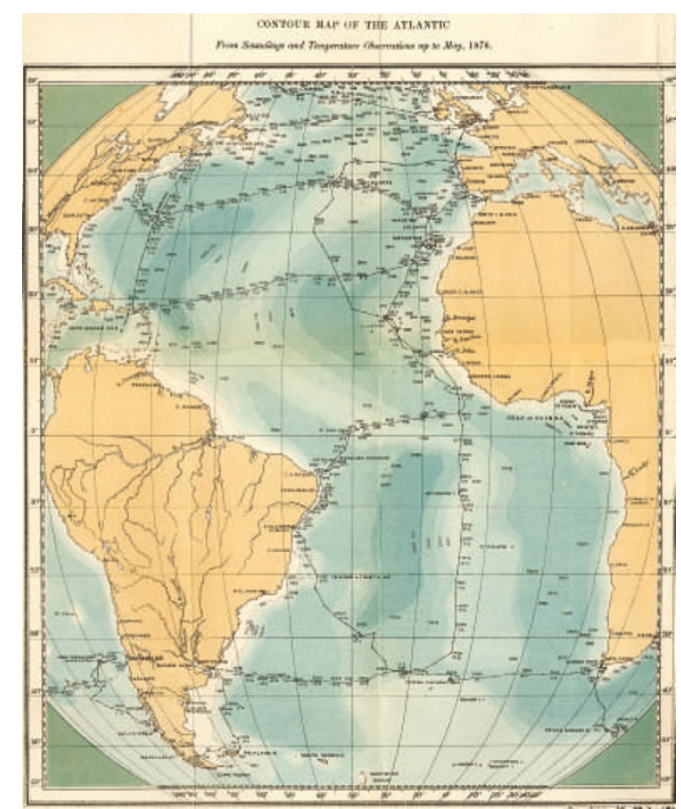

In-depth study: Wyville Thomson's map shows that the Challenger expedition revealed the Mid-Atlantic Ridge.

the ocean was restricted to shallow depths where sunlight can penetrate. Scientific questions, practical needs, the projection of a global presence - all these could be related to subsequent global science initiatives.

Such a panorama opens a broad array of choices for the modern writer. Richard Corfield has elected to give us a short, readable volume that combines an abbreviated version of the expedition, snapshots of personal accounts of some of its participants, modern perspectives on selected scientific problems, and reflections on modern research vehicles in ocean drilling and space that have adopted the Challenger's name.

The book is an entertaining and informative combination of history and modern science. It fits with the recent enthusiasm for books on historical geology, such as The Map that Changed the World (Viking, 2001) by Simon Winchester, and should appeal to the same audience. Many of the expedition's logistical details, showing the ingenuity and foresightedness of these pioneering oceanographers, will also amuse and appeal to the modern sea-going scientist.

The decision to keep the book short means that some scientific aspects of the expedition get little attention, and specialists may be disappointed by the superficiality of, and occasional scientific errors associated with, the treatment of some modern developments. This book nicely covers the modern outgrowth of climate science that stems from Challenger's discoveries, but another author could equally have written a book emphasizing the Challenger results that presaged plate tectonics or influenced our understanding of evolution and biodiversity. Corfield devotes only a few pages to plate tectonics, and refers disparagingly to the "tedium of dredging and sounding". For those who appreciate it, however, scientific dredging is almost always exciting, as it penetrates the unknown depths and brings back from the bottom materials never before seen by human eyes. It was dredging that brought back the sediments, provided the first samples of the basalts that make up the ocean ridges, and recovered the thousands of new species documented by Challenger's biologists.

Can we learn anything today as we reflect on the discoveries of the Challenger expedition? Perhaps they serve to remind us of the limits of our imagination, and that the answers we receive are often limited by the questions we are able to ask. In the late nineteenth century, Earth was thought to be static, with limited horizontal motion. Continental drift had not yet been proposed, so questions of movement and of changes to the shape of the ocean basins never came to mind. And yet Wyville Thomson, who died of exhaustion shortly after the expedition ended, may have had some premonition of what was to come. An elegant frontispiece in his book summarizing the expedition reveals a map of the Mid-Atlantic Ridge, fully recognizable in remarkable detail. Thomson also noted without further comment that the ridge closely matched the shape of the coastlines on the two sides of the Atlantic. The facts were there; the questions were not. Similar observations, and the more detailed map produced by Bruce Heezen and Marie Tharp some 80 years later, were central to the discovery of plate tectonics, which revealed that the solid Earth is continually in movement and circulation. Which of today's observations will prove most interesting when we know what questions to ask?

One characteristic of a successful book is that one puts it down longing for more. Within its chosen limits, The Silent Landscape is indeed successful. It provides the history and excitement of an epic voyage in the context of modern developments. It does so in a brief and readable form, and leaves ample scope for deeper explorations of such rich historical material.

Charles Langmuir is in the Department of Earth and Planetary Sciences, Harvard University,

Cambridge, Massachusetts 02138, USA. 